\title{
Nacionalismo, marxismo e intelectuales en la Argentina de los años cincuenta. Un emprendimiento editorial para un encuentro posible
}

\author{
Nationalism, Marxism and intellectuals in the Argentina of the fifties. A \\ publishing project for a possible meeting
}

\author{
Cecilia Gascó*
}

\begin{abstract}
Resumen: Este trabajo propone un análisis de la revista Columnas del Nacionalismo Marxista. Avanzada para el Frente de Liberación Nacional, publicada en Buenos Aires en 1957, con el objetivo de identificar cuáles son los ejes y tópicos de debate que postula el nacionalismo a partir del derrocamiento del gobierno de Juan D. Perón en 1955, cómo se vincula con su propia tradición y de qué modo presenta la "cuestión nacional" en su articulación con ideas y conceptos provenientes del marxismo.
\end{abstract}

Palabras clave: Nacionalismo, Marxismo, Cuestión nacional, Análisis de revista

\begin{abstract}
This work proposes the analysis of the Marxist Nationalism Notes. For the National Liberation Front magazine, published in Buenos Aires in 1957, with the objective of identifying lines and topics of the debate postulated by the Nationalism after the overthrow of the Juan D. Perón government, how the nationalists link themselves with their own tradition and how they consider the "national issue" in articulation with the ideas and concepts from the Marxism.
\end{abstract}

Keywords: Nationalism, Marxism, National problem, Magazine analysis

Recibido: 15 diciembre 2016

Aceptado: 9 marzo 2017

\footnotetext{
" Argentina. Profesora IES N" 1 "Alicia Moreau de Justo". Investigadora en Formación, Proyecto: "Peronismo, izquierda y prensa escrita. Los intelectuales marxistas como periodistas políticos (1945-1955)", dirigido por el Mg. Marcelo Summo (UNTREF Argentina - Programación Científica 2016-2018). mariaceciliagasco@gmail.com
} 


\section{Introducción}

El golpe de Estado de 1955 que derrocó al gobierno de Juan D. Perón inauguró una etapa que implicó diversos y profundos cambios. En el espacio cultural, distintos sectores iniciaron un camino para comprender y analizar el proceso que en los años precedentes había modificado sustancialmente la vida política y social argentina. "Pensar el hecho peronista" se volvió un imperativo, como plantea Oscar Terán, ${ }^{1}$ y a ello se dedicaron grupos de intelectuales que ya desde los años finales del gobierno peronista habían comenzado una indagación sobre la realidad nacional desde enfoques renovados, porque consideraban que los esquemas tradicionales ya no eran útiles para comprender la nueva sociedad.

Propuestas como la revista Contorno, liderada por los hermanos Ismael y David Viñas ${ }^{2}$, los trabajos historiográficos de miembros disidentes del Partido Comunista (PC) vinculados con el peronismo, como Eduardo Astesano y Rodolfo Puiggrós, ${ }^{3}$ e incluso miradas cuestionadoras de las premisas liberales expresadas desde las mismas páginas de Sur demuestran la diversidad de lecturas que se produjeron a mediados de la década del cincuenta y cómo, al mismo tiempo, dentro de cada sector se iban produciendo reacomodamientos y también fisuras. ${ }^{4}$

En este contexto, la revista Columnas del Nacionalismo Marxista. Avanzada para el Frente de Liberación Nacional (Columnas...), publicada en 1957, expresa las lecturas que promovieron sectores nacionalistas a partir de su vinculación con la teoría marxista. Es uno de los emprendimientos editoriales surgidos en medio de los debates y también al calor de las primeras elecciones realizadas luego del derrocamiento de Perón, que tenían como objetivo conformar una Asamblea Constituyente para reformar la Constitución de 1853. Allí los nacionalistas discuten con su propia tradición y entablan un diálogo con intelectuales marxistas con el propósito de dar forma a una corriente de pensamiento y acción con eje en el antiimperialismo, la alianza policlasista y el nacionalismo económico.

La relación entre "clase" y "nación” ha sido un tema abordado tanto por Marx, ya desde sus primeros escritos, como por Lenin, Rosa Luxemburgo y otros representantes relevantes del

\footnotetext{
${ }^{1}$ Terán, Oscar. Historia de la ideas en la Argentina. Diez lecciones iniciales, 1810-1980. Buenos Aires: Siglo XXI editores, 2008, 257.

${ }^{2}$ Sobre la revista Contorno se puede consultar Croce, Marcela. Contorno. Izquierda y proyecto cultural. Buenos Aires: Ediciones Colihue, 1996 ó Warley, Jorge. "La revista Contorno: literatura, cultura, política e historia en el ocaso del peronismo histórico" en Sosnowski, S. (ed.) La cultura de un siglo. América Latina en sus revistas. Buenos Aires: Alianza Editorial, 1999

${ }^{3}$ Para más información sobre Astesano y Puiggrós consultar Tarcus, Horacio (dir.) Diccionario biográfico de la izquierda argentina. De los anarquistas a la "nueva izquierda" (1870-1976). Buenos Aires: Emecé, 2007. ${ }^{4}$ Sobre la revista Sur ver King, John. Sur. Estudio de la revista argentina y de su papel en el desarrollo de una cultura. 1931-1970. México: FCE, 1986 / Gramuglio, M. Teresa. "Sur, constitución del grupo y proyecto cultural", en Punto de Vista, N 17, Buenos Aires, 1983, ó "Sur en la década del treinta: una revista política", en Punto de Vista, $\mathrm{N}^{\circ} 28$, Buenos Aires, 1986.
} 
marxismo durante el siglo XX. En Argentina, el surgimiento del peronismo impulsó a teóricos y a pensadores de izquierda con formación marxista a abordar nuevamente la cuestión nacional y a ensayar diversas respuestas ante el desafío que implicaba la existencia de un movimiento político que postulaba la alianza de clases y que contaba con el apoyo masivo de los sectores obreros.

Este trabajo propone un análisis de la revista Columnas... con el objetivo de identificar cuáles son los ejes y tópicos que postula el nacionalismo a partir de la caída del gobierno peronista, cómo se vincula con su propia tradición y de qué modo presenta la "cuestión nacional" en su articulación con ideas y conceptos provenientes del marxismo.

Existen muchos estudios sobre el origen y el desarrollo del nacionalismo y su vinculación con otras vertientes ideológicas. Específicamente, la articulación del nacionalismo con las corrientes de pensamiento de izquierda ha sido abordada por trabajos historiográficos que dan cuenta de cómo a partir de la década de 1930 esa convergencia y, unos años más tarde, la consideración de la "cuestión nacional" desde las lecturas marxistas fueron dando origen, entre otras producciones, a nuevos relatos sobre la historia argentina que disputaron la hegemonía a la versión liberal que se había impuesto a principios del siglo XX. ${ }^{5}$

A partir de 1955, la proscripción al peronismo y la existencia de sectores de izquierda que se oponían al régimen militar fueron generando las condiciones para el surgimiento de renovados núcleos de ideas que actualizaron la articulación entre el pensamiento nacional y las lecturas provenientes del marxismo. En el campo de la izquierda, la revista Contorno, nacida en 1953 durante el gobierno de Perón, se constituyó como uno de los importantes referentes de la vinculación entre cultura y política que se proponía impugnar la tradición literaria elitista a partir de la lectura de la realidad nacional desde el Marxismo y el Existencialismo. Ejercía la crítica tanto hacia el peronismo como al antiperonismo, por lo cual fue para Flavia Fiourucci, que investigó la relación entre intelectuales y peronismo, "vehículo de un discurso atípico en el debate intelectual de la época"6 y su influencia ha sido abordada desde la historiografía y los estudios culturales. ${ }^{7}$ Luego del golpe, surgieron también publicaciones clandestinas o semiclandestinas que reflejaban diferentes y variadas procedencias ideológicas y buscaban difundir propuestas políticas para resistir la prohibición. En estas revistas, de existencia breve y circulación restringida, fue donde el nacionalismo comenzó a dialogar con otras corrientes de pensamiento. Son emprendimientos que no han sido suficientemente estudiados pero constituyen documentos de una etapa de transición en la que se fueron gestando experiencias y prácticas dentro del

\footnotetext{
5 Se pueden consultar: Buchrucker, Cristian. Nacionalismo y peronismo. Buenos Aires: Editorial Sudamericana, 1987 / Devoto, Fernando. Nacionalismo, fascismo y tradicionalismo en la Argentina moderna. Una historia. Buenos Aires: Siglo XXI de Argentina Editores, 2002 y "Reflexiones en torno de la izquierda nacional y la historiografía argentina", en Devoto, Fernando y Nora Pagano (Editores) La historiografía académica y la historiografía militante en Argentina y Uruguay. Buenos Aires: Biblos, 2004 / Lvovich, Daniel. El nacionalismo de derecha. Desde su orígenes a Tacuara. Buenos Aires: Capital Intelectual, 2006.

${ }^{6}$ Fiorucci, Flavia. Intelectuales y peronismo. 1945-1955. Buenos Aires: Editorial Biblos, 2011.

${ }^{7}$ Croce, Marcela. Contorno. Izquierda y proyecto cultural. Buenos Aires: Ediciones Colihue, 1996.
} 
peronismo que formarían parte de la conocida "Resistencia" y que permiten conocer cómo se combinaron elementos del pensamiento nacional con ideas provenientes del marxismo.

En este contexto, y a pesar de su breve duración, el abordaje de la revista Columnas... permite construir un estudio de caso para identificar y analizar diferentes tópicos que confluyeron en el debate político abierto a partir de la destitución de Perón en 1955: la "cuestión nacional", los replanteos y la autocrítica de la izquierda tradicional, las lecturas marxistas y los lineamientos ideológicos y doctrinarios del peronismo que, lejos de debilitarse por la ausencia del líder, se consolidaron como ejes de resistencia al régimen de facto y se enmaracaron dentro de la lucha antiimperialista que caracterizaba a gran parte de los movimientos latinoamericanos nacionalistas de los años cincuenta.

El análisis de la publicación se realiza desde la perspectiva de la historia intelectual, que vincula las creaciones culturales con su contexto de producción y las ubica en las redes de sociabilidad por donde circulan y comparten un universo de autores, ideas y conceptos. Se trata de articular la historia política con la cultural, atendiendo tanto a los procesos históricos en donde se generan los productos como al lenguaje que utilizan y a los sentidos que generan y convocan. De este modo, el trabajo asume las premisas propuestas por Carlos Altamirano que define a la historia intelectual como un campo de estudios para el cual “...Su asunto es el pensamiento (...) en el seno de experiencias históricas"8 y ubica a Columnas...como parte de una formación intelectual, tal como la define Raymond Williams, que, impugnando las tradiciones e instituciones formales, produjo una significativa y perdurable influencia político-cultural a través de la creación de nuevos relatos y de un programa político nacionalista y antiimperialista. ${ }^{9}$

Con estas premisas y a partir de las líneas de análisis que proponen Girbal-Blacha y Quatrocchi-Woisson en su trabajo sobre las revistas argentinas del siglo XX, consideradas como objetos fundamentales para comprender las tradiciones políticas ${ }^{10}$, el artículo presenta una indagación sobre el contenido de Columnas..., sus temas, colaboradores, ejes de debate y tradiciones políticas en las que abreva o a las que discute, como un aporte para comprender la relación de las izquierdas con la cuestión nacional.

\section{La tradición política y cultural del Nacionalismo}

Desde fines de la década de 1920, un grupo de intelectuales entre los que se encontraban los hermanos Julio y Rodolfo Irazusta, Carlos Ibarguren y Ernesto Palacio había

\footnotetext{
${ }^{8}$ Altamirano, Carlos. Para un programa de historia intelectual y otros ensayos. Buenos Aires: Siglo XXI, $2005,10$.

9 Williams, Raymond. Marxismo y literatura. Buenos Aires: Las Cuarenta, 2009, 161.

${ }^{10}$ Girbal-Blacha, Noemí y Diana Quattrocchi-Woisson. Cuando opinar es actuar. Revistas argentinas del siglo XX. Buenos Aires: Academia Nacional de la Historia, 1999.
} 
comenzado a articular un conjunto de ideas que daría lugar a la construcción de un nacionalismo elitista, jerárquico y conservador. A través de obras como La Argentina y el imperialismo británico o La historia falsificada inauguraron la corriente historiográfica revisionista, presentándose como la alternativa a la versión histórica liberal dominante desde Caseros, a la que llamaron desde entonces "historia oficial". Este nuevo universo cultural promovía claramente una alternativa política a la democracia liberal y a los principios de igualitarismo heredados de la tradición revolucionaria francesa. Con el objetivo de salvar la república, a la que veían amenazada por el caos y la corrupción, promovieron la caída del gobierno de Hipólito Yrigoyen en 1930 y creyeron encontrar en el General Uriburu al líder que llevaría sus consignas al poder. Sin embargo, al año siguiente vieron fracasar el proyecto corporativo uriburista y se desilusionaron por la alianza gubernamental con los conservadores que iniciaría la etapa del fraude electoral sistemático vigente hasta 1943.

El historiador Fernando Devoto plantea que "El nacionalismo político no culmina, ciertamente, en 1932. Alguien podría afirmar que es ahí cuando comienza." ${ }^{11}$ En los años treinta se consolidaron ciertos tópicos e interpretaciones de la historia argentina que luego fueron retomados, actualizados, resignificados $\mathrm{o}$ articulados con otras corrientes de pensamiento o formaciones políticas que dieron lugar a nuevos núcleos nacionalistas. En este sentido, la emergencia del peronismo implicó una reconfiguración al interior del campo nacionalista, con rupturas, pasajes y adhesiones de algunos de sus representantes al nuevo movimiento que impulsaba Perón. En aquellos años se acentuó la diversidad ideológica y, más allá de los elementos comunes que giraban en torno a los conceptos de nación y antiimperialismo, no todos adhirieron al peronismo o manifestaron devoción a Rosas.

Si el primer nacionalismo, elitista y antiimperialista a la vez, había surgido en medio del predominio mundial del fascismo y cuando el marxismo era una cuestión marginal en los ámbitos culturales locales, la corriente de izquierda nacional que comenzó a gestarse durante los años finales del gobierno peronista nacía y se consolidaba en medio de la difusión creciente del marxismo en Argentina y en el mundo. En ese contexto, Devoto postula que en 1957 Columnas... refleja anticipadamente el heterogéneo conglomerado ideológico que se hará popular a fines de la década del sesenta. ${ }^{12}$ En sus páginas se pueden identificar parte de las lecturas sobre la realidad argentina que promovieron los nacionalistas en la década de 1950 a partir de su vinculación con la teoría marxista. Allí escribieron, entre otros, Fermín Chávez, Eduardo Astesano y Elías Castelnuovo, quienes

\footnotetext{
${ }^{11}$ Devoto, Fernando. Nacionalismo, fascismo y tradicionalismo en la Argentina moderna. Una historia. Buenos Aires: Siglo XXI de Argentina Editores, 2002, 279.

${ }^{12}$ Devoto, Fernando. "Reflexiones en torno de la izquierda nacional y la historiografía argentina", en Fernando Devoto y Nora Pagano (Editores) La historiografía académica y la historiografía militante en Argentina y Uruguay. Buenos Aires: Biblos, 2004, 107-130.
} 
con sus distintas procedencias ideológicas y adscripciones políticas confirman la idea de diversidad que menciona Devoto.

\section{Columnas del Nacionalismo Marxista. Claves para una nueva articulación político-cultural en torno a la "cuestión nacional"}

Columnas... expresa una de las nuevas articulaciones políticas y culturales que luego de la destitución Perón buscaron construir las bases de un proyecto para la "liberación nacional". Columnas...propuso un camino para la afirmación de la identidad nacional a través de ideas y conceptos provenientes del marxismo y del nacionalismo articulados en torno a una posición antiimperialista.

La revista editó tres números en 1957 y fue dirigida por Eduardo Astesano, un abogado nacido en Córdoba pero con residencia temprana y formación en la provincia de Santa Fe, que había militado en el Partido Comunista (PC) argentino hasta que fue expulsado en 1947 junto con Rodolfo Puiggrós por su acercamiento al peronismo. El costo era de cinco pesos $\mathrm{y}$, si bien indicaba que era una revista quincenal que aparecía el segundo y cuarto domingo de cada mes, sus tres ediciones aparecieron mensualmente: en julio, agosto y setiembre, y cada una de ellas constó de 32 páginas. El diseño gráfico era simple, con su título como motivo excluyente en una tapa que fue variando sus colores con cada número, manteniendo la ilustración de una columna de gente que se manifiesta en las calles, marchando hacia adelante y portando una bandera argentina. Las personas representadas no se asemejan a las figuras con las que se solía identificar a la clase obrera, con el típico overol masculino del trabajador o "descamisado" o la mujer con vestimenta sencilla, asociada a las tareas del hogar, motivos clásicos de la iconografía peronista ${ }^{13}$, sino que son hombres con saco y corbata y mujeres que podrían ser oficinistas más que obreras o amas de casa. En este sentido, desde su imagen de tapa, la revista parece apuntar más a la representación de los sectores medios que a convocar a los sectores populares y trabajadores desde una perspectiva clasista.

La publicación se propone como un espacio de encuentro e intercambio entre el pensamiento nacionalista y la teoría marxista, en el contexto del gobierno de facto del general Aramburu y en el año en que se producen las primeras elecciones luego del derrocamiento de Perón, que tenían como objetivo la conformación de una Asamblea Constituyente para reformar el texto constitucional de 1853. Esta situación política, aludida en varios de los artículos, es presentada como la evidencia del poder de resistencia del pueblo que con su voto dijo "no" a la iniciativa de un gobierno "ilegal y prepotente" que buscaba destruir todas las conquistas políticas y sociales obtenidas en los años precedentes.

\footnotetext{
${ }^{13}$ Gené, Marcela. Un Mundo Feliz: Imágenes de los trabajadores en el primer peronismo 1946-1955. Buenos Aires: Fondo de Cultura Económica, 2005.
} 
Como señala Devoto, la revista condensa gran parte de los tópicos que se volverán centrales hacia fines de la década de 1960, no sólo en las producciones historiográficas sino a través de obras de divulgación de una historia nacional que se presenta como alternativa a la historia oficial y que alcanzará a grandes públicos a través de libros y publicaciones de tiradas masivas. En sus páginas es posible reconocer la línea denuncialista con la que surgió el nacionalismo durante los años treinta. La idea que atraviesa a la revista es que el imperialismo ha impuesto la división entre países dominantes y países coloniales y ha generado la dependencia económica y cultural de Argentina y de todos los países de América Latina. La continua injerencia de las grandes potencias, y de Inglaterra principalmente en el Río de la Plata desde 1810, vuelve urgente la tarea de trabajar para la liberación nacional. La soberanía política sólo podrá alcanzarse a partir de una independencia económica basada en la promoción industrial y en un Estado nacional empresario que garantice el desarrollo de la siderurgia a gran escala y el autoabastecimiento petrolero.

En el primer número, Fermín Chávez postula la línea editorial en su artículo "Nacionalismo y marxismo", donde señala los principales tópicos y ejes de debate que atravesarán a las tres ediciones. Chávez se define como nacionalista, no marxista, pero afirma que el bombardeo a la Plaza de Mayo organizado por la Marina en 1955 terminó con ciertos prejuicios ideológicos que impedían el diálogo entre ambas corrientes e impuso como necesidad ponerse al servicio de la patria ante el "enfrentamiento entre pueblo y oligarquía". ${ }^{14}$ Es por ello que la revista se presenta no sólo como un espacio de reflexión teórica e ideológica sino como una empresa cultural con el objetivo de intervenir políticamente a través del llamado a la conformación de un Frente Nacional.

Chávez reconoce que el nacionalismo de sus "maestros" fue impulsado por una minoría de la clase media y de la pequeña burguesía y, por lo tanto, en aquella primera configuración convivían tanto elementos conservadores como liberales. "Nacimos antimarxistas" afirma, pero para señalar inmediatamente después que en 1957 el acercamiento entre marxismo y nacionalismo es un hecho real. La tarea que se propone el nacionalismo de la década del cincuenta es abandonar las ficciones ideológicas que hasta entonces predominaron no sólo entre conservadores y liberales sino también en los comunistas. Para el autor, el PC también se alinea en la concepción liberal de la historia y por ello ha sido incapaz de reconocer y acercarse al pueblo concreto, portador de prácticas políticas y hábitos culturales propios.

Para vincularse con ese país real es imprescindible, según Chávez, que tanto el nacionalismo como el marxismo corrijan graves errores. Los marxistas deben acercarse a la nación como hecho histórico, abandonando la perspectiva clasista que enfrenta al proletariado con la nación. Por su parte, el nacionalismo debe dejar de ser burgués y acercarse a las masas porque de lo que se trata es de acercar realidades y no ficciones ideológicas.

\footnotetext{
${ }^{14}$ Chávez, Fermín. "Nacionalismo y marxismo" en Columnas del Nacionalismo Marxista. Avanzada de Frente Nacional. $\mathrm{N}^{\circ}$ 1, Julio de 1957, 1-4.
} 
En la edición siguiente, Chávez retoma la crítica al liberalismo y a la "democracia de doctorcitos y levitas" "15, opuesta a la democracia de los caudillos populares como Artigas, Facundo, Rosas o Perón. De este modo, ubica a la revista en la tradición revisionista que en la década de 1930 había impugnado tanto a la historia liberal construida por Bartolomé Mitre como a la política rivadaviana, por considerarla expresión del centralismo impulsado por una minoría porteña. Chávez analiza además al demoliberalismo del PC y concluye que al compartir con la tradición liberal sus ideas de progreso y laicismo, los comunistas responden también a la línea Mayo-Caseros, que desconoce las luchas populares y toma como sus próceres a Mitre, Lavalle y Rivadavia. El Partido Socialista (PS) tampoco escapa a la crítica, son para la revista "jóvenes de clase media, intelectuales y pobretes subestimados por la oligarquía"16

Astesano, el director de la revista también escribe artículos en los que despliega sus análisis sobre el peronismo como ejemplo de una revolución nacional que contenía dos elementos esenciales: la lucha antiimperialista y la preeminencia del rol del Estado como organizador de una economía nacional industrialista. Contaba, además, con un claro y masivo apoyo de la clase obrera. Desde entonces, dedicó sus trabajos a analizar y comprender el nuevo fenómeno político articulando su previa formación teórica marxista con una perspectiva nacional. Con estas ideas publicó en 1953 su Ensayo sobre el Justicialismo a la luz del materialismo histórico, en el que combina una dura crítica a los "falsos enfoques" sobre el peronismo por parte de la conducción del PC, debido a su conformación pequeño burguesa y su falta de sensibilidad hacia las cuestiones nacionales, junto a un análisis del peronismo en el que intenta develar las fuerzas que lo sostienen y el nuevo rol del Estado que ha surgido a partir de la "revolución justicialista". 17

Junto a Chávez, proveniente del nacionalismo, y a Astesano, con formación en el materialismo histórico y en el maoísmo, participaban escritores de diversas procedencias: Elías Castelnuovo, que había iniciado su militancia en el PC pero luego había adherido al peronismo; Juan Pablo Oliver, historiador revisionista; Arturo Sampay, abogado de ideas yrigoyenistas que se sumó también al peronismo y Antonio Nella Castro, un escritor salteño que dedicó gran parte de sus obras a retratar a los sectores populares.

Si bien proceden de diferentes posiciones políticas e ideológicas, todos comparten la línea antiimperialista plasmada en Columnas...Los textos de unos parecen complementar los de otros y a través de la lectura de los diversos artículos es posible identificar a los actores sociales que resultan imprescindibles en el proceso de liberación. El ejército argentino es

\footnotetext{
${ }^{15}$ Chávez, Fermín. "Los comunistas y la línea Mayo-Caseros”, en Columnas del Nacionalismo Marxista. Avanzada de Frente Nacional. $\mathrm{N}^{\circ}$ 2, Agosto de 1957, 25-26.

${ }^{16}$ Ver recuadro en Columnas del Nacionalismo Marxista. Avanzada de Frente Nacional. $\mathrm{N}^{\circ} 2$, Agosto de $1957,24$.

${ }^{17} \mathrm{Cfr}$. Amaral, Samuel. Una interpretación maoísta del peronismo: Eduardo Astesano y la revolución de la nueva democracia. Univ. del CEMA. Series documentos de trabajo no 279 Área Ciencias Políticas. Dic. 2004 en www.UCEMA.edu.ar/publicaciones
} 
uno de los puntales necesarios para construir una patria independiente y soberana, por lo cual su misión no sólo debe consistir en cuidar las fronteras geográficas sino en establecer una sólida y duradera alianza con el pueblo que permitirá enfrentar a las potencias imperialistas y a la oligarquía argentina que ha actuado como su agente local.

Sin embargo, la idea de pueblo no responde a una noción sociológica o derivada de la concepción de clase marxista, sino que se lo presenta como una vaga idea: se lo asocia a los "cabecitas negras" o se lo representa a través de la figura de "Juan Pueblo." En el artículo "Sólo una vez, amigo Jauretche", Remigio Alderete, que se identifica como un escritor de campo y "cabecita negra" del Fortín "El Saladillo" en la provincia de Córdoba, traza una historia de las luchas populares a través de la figura de "Juan Pueblo": "No tropezó cuando fue bajo las banderas de don Juan Manuel de Rosas a morir en defensa del honor criollo y de la soberanía nacional, mientras los "ascuosos" de entonces y los militares gorilas, que también los había en aquel tiempo, le gritaban que volteara al "sangriento tirano" desde atrás de los faldones de los Braden de entonces." 18

El pueblo es portador de bondad y sabiduría. En el segundo número, Columnas... publica un texto de John W. Cooke, "El pueblo salió fortalecido", escrito el 30 de Julio de 1957desde su exilio en Santiago de Chile. Allí, el autor se refiere al gobierno de facto como "Grupo de Ocupación" que mediante el "monstruoso decreto-ley 4161" había disuelto el partido peronista pero había generado también una voluntad de resistencia. Hay aquí también una representación épica del pueblo:

Una vez más, los humildes están solos en la defensa de la dignidad y los intereses nacionales. Pero siempre ha sido así. La historia enseña que cuando la traición oligárquica abre las puertas a la voracidad del imperialismo, la tierra opone el coraje de sus hijos, y la Patria se enciende en holocaustos gloriosos y fecundos. Esta generación está dispuesta a cumplir con el sacrificio que demandan de ella una tradición inmaculada y una esperanza inextinguible. ${ }^{19}$

Cooke, uno de los principales promotores de la articulación del peronismo con el marxismo, comparte con los editores de Columnas... la perspectiva antiimperialista y el reconocimiento del pueblo como actor principal para alcanzar la liberación nacional. En ese mismo número se transcribió un editorial que la revista De Frente, dirigida por Cooke, había publicado en 1955. Entre 1953 y 1956, ese emprendimiento editorial se identificó con el peronismo pero buscó diferenciarse de sus "rasgos autoritarios y burocratizantes" planteando la necesidad de una mayor democratización en sus prácticas políticas. Como

\footnotetext{
${ }^{18}$ Alderete, Remigio. "Sólo una vez, amigo Jauretche”, en Columnas del Nacionalismo Marxista. Avanzada de Frente Nacional. $\mathrm{N}^{\circ}$ 1, Julio de 1957, 29-31.

${ }^{19}$ Cooke, John W. "El pueblo salió fortalecido", en Columnas del Nacionalismo Marxista. Avanzada de Frente Nacional. N $^{\circ}$ 2, Agosto de 1957, 28-29.
} 
afirma Mario Ranalletti: "De Frente será una revista peronista, pero no oficialista". ${ }^{20}$ Esta publicación analizaba temas similares a los que abordó luego Columnas..., como la importancia del autoabastecimiento petrolero, y adhería también a los planteos historiográficos revisionistas.

Sólo uno de los artículos de la revista, "Nuestra clase obrera debe integrarse en la Nación", escrito por Antonio Castro en el número dos, postula un análisis más riguroso de la posición estratégica que un programa económico nacional debe otorgarle a los sectores trabajadores: “(...) si algún sentido tiene el concepto de integración en lo nacional de la columna vertebral proletaria es, precisamente, su integración en las ganancias de cada empresa, para bien suyo, de la empresa y de la sociedad en su conjunto." 21

Para sostener sus premisas o identificar a los males que aquejan históricamente al país, la revista construye paralelismos entre el siglo XIX y el XX. El rol de Rosas en la defensa de la soberanía nacional y en la organización de un orden económico estable es presentado por Astesano como el comienzo de un desarrollo capitalista nacional que luego el peronismo fortaleció con la promoción industrial y la consolidación de la clase obrera. También para Chávez, Rosas y Perón son los caudillos que, junto a Artigas y Facundo, representan la democracia popular, opuesta a la democracia liberal de Mitre, Lavalle y Rivadavia. La Constitución unitaria de 1826 es la expresión de los intereses de la minoría porteña, así como lo es la que ellos están impugnando en 1957, promovida por el gobierno de facto.

La línea "Mayo-Caseros" representa la ideología liberal que por 100 años ha dominado al país y lo ha condenado a la dependencia y a la injerencia constante del capital extranjero. Frente a ella, la revista presenta su propia línea, que retoma algunas de los tópicos y figuras que ya los nacionalistas de la década del treinta habían instaurado: el gobierno de Rosas como la contraparte del "entreguismo" de Rivadavia y el rol nocivo del capital inglés como agente del imperialismo. Pero el nacionalismo que expresa Columnas... también introduce en su panteón de próceres a Artigas y lo ubica en la misma línea que a San Martín. Reconoce, además, a Carlos Pellegrini y a los generales Savio y Mosconi por su defensa de la industria nacional. Si el nacionalismo de los treinta alentó el clima opositor al gobierno de Yrigoyen y al golpe de Estado que finalmente lo derrocó, el nacionalismo que expresa e impulsa Columnas... se define ante todo como popular, cercano al pueblo e incluye a Yrigoyen "del lado de los buenos". La consigna del momento es la liberación y así como en

\footnotetext{
${ }^{20}$ Ranalletti, Mario. "De Frente (1953-1956) Una voz democrática y antiimperialista en la crisis final del primer peronismo", en Noemí Girbal-Blacha y Diana Quattrocchi-Woisson. Cuando opinar es actuar. Revistas argentinas del siglo XX. Buenos Aires: Academia Nacional de la Historia, 1999.

${ }^{21}$ Castro, Antonio. "Nuestra clase obrera debe integrarse en la Nación", en Columnas del Nacionalismo Marxista. Avanzada de Frente Nacional. N 3, Setiembre de 1957, $16-19$.
} 
el siglo XIX la impulsaron gauchos y caudillos al grito de "Federación o Muerte!", en el presente es "Soberanía o Muerte". 22

Para reforzar y avalar sus premisas, Columnas... recurre a la inclusión de la perspectiva marxista con recuadros en los que se transcriben fragmentos de textos de Carlos Marx, en donde resalta la importancia de que las masas se apropien de la teoría, o de Paul Sweezy, con ideas del economista que destacan la importancia que tiene la actuación del ejército junto al pueblo en la afirmación nacional de los países oprimidos.

Con estas operaciones de inclusión, reconocimiento y resignificación, Columnas... identifica claramente amigos y enemigos, definidos en relación a cuánto favorecen u obstaculizan el proceso de liberación nacional. El pueblo, el ejército, el Estado nacional como agente económico, el desarrollo industrial y los derechos adquiridos con la Constitución de 1949 son los factores que representan la soberanía nacional y promueven la independencia que pondrá fin al dominio imperialista. Por el contrario, la Constitución de 1853, la actitud de la burguesía local, que facilita la injerencia de los grandes capitales extranjeros, y los partidos Comunista y Socialista, siempre ajenos a la clase obrera local, son identificados como responsables de la vigencia de un liberalismo económico que sólo ha perjudicado a la economía nacional al impedir el desarrollo de una industria pesada y de gran escala, verdadero sostén y garantía de una patria soberana e independiente.

La revista manifiesta una crítica persistente al liberalismo, al comunismo y al socialismo, por el desconocimiento o subestimación que todos han demostrado históricamente hacia la cuestión nacional. En este sentido, Columnas... continúa la línea crítica de los nacionalistas de la década de 1930, que adjudicaban a la "ciudad puerto" y al predominio del mercantilismo porteño el carácter dependiente de la economía argentina.

Del mismo modo, la gran prensa, representada especialmente por el diario La Nación, es acusada de responder a la línea "Mayo-Caseros", por reproducir los tópicos liberales y convertirse así en agente del colonialismo, que no sólo determinaba la forma de las economías dependientes sino que moldeaba el pensamiento e impedía reconocer la propia condición de sumisión. El "coloniaje", por eso mismo, debía ser contrarrestado por una batalla cultural que era también imprescindible en el camino hacia la liberación. En este tema, los artículos de Elías Castelnuovo se encargaban de señalar la importancia de nacionalizar la cultura y oponer una resistencia constante a las "lacras" que el viejo mundo exportaba al nuevo, porque el imperialismo también penetraba a través de las manifestaciones culturales: los libros, el cine y la radio eran agentes del coloniaje tanto como lo eran los grandes bancos, e incluso peor en tanto se presentaban como portadores de los valores universales de la cultura y la ilustración. ${ }^{23}$

\footnotetext{
${ }^{22}$ Belavita, Victorio. “Soberanía o muerte!!!”, en Columnas del Nacionalismo Marxista. Avanzada de Frente Nacional. $\mathrm{N}^{\circ}$ 1, Julio de 1957, 8-10.

${ }^{23}$ Castelnuovo, Elías. "El viejo mundo exporta sus lacras al nuevo mundo", en Columnas del Nacionalismo Marxista. Avanzada de Frente Nacional. № 3, Setiembre de 1957, 20-22.
} 
Las definiciones y objetivos políticos de la revista se plasman en los editoriales, ubicados en las páginas finales de cada número. Allí, se señala la importancia del voto en blanco, bandera sobre la que debe construirse un Frente Nacional y Popular, sin sectarismos ni exclusiones partidarias. Esta unión debe sostenerse sobre el vínculo entre la clase media nacional y la clase obrera, acuerdo sobre el que se basó el peronismo entre 1945 y 1955 gracias a una "hábil conducción política" que logró superar dos limitaciones fundamentales: el antiobrerismo, presente entre civiles y militares, y el sectarismo obrero de tradición anarquista, socialista o comunista, siempre renuente a las alianzas intersectoriales.

Los tres editoriales ponen énfasis en la máxima flexibilidad con que debe manejarse el Frente Nacional, todas las posibles contradicciones internas deben subordinarse a la lucha antiimperialista. Según los editores, gracias a la "intuición política de la clase trabajadora", el voto en blanco había abierto el camino hacia la liberación nacional y había hecho evidente que, aún con el líder en el exilio, el partido peronista era su partido de clase.

\section{La "cuestión nacional” en los países de Europa del Este}

Columnas... también demuestra un acercamiento e interés por la "cuestión nacional" que se está planteando en los años cincuenta en los países de Europa del Este. La situación es abordada como un tema de actualidad internacional que debe ser conocido y comprendido porque da cuenta de otro de los modos de actuar del imperialismo vigente y por ello se incluye una serie de trabajos de escritores que presentan un panorama de los marxismos y su relación problemática con la URSS.

Se reproducen textos en los que se describe las situaciones de Polonia y Yugoslavia que, a partir de 1948, buscaron mantener su independencia frente a la injerencia de la potencia dirigente del bloque oriental. De la revista yugoslava "Cuestiones actuales del socialismo" se reproduce el artículo "Marxismo y patriotismo", escrito por Ales Bebler, un representante diplomático ante la Organización de Naciones Unidas que desarrolla una serie de argumentos para dar cuenta de la concepción nacional presente en las ideas de Marx. Con este propósito, afirma que el marxismo no implica la negación de la patria y el pueblo, por el contrario, sostiene que internacionalismo y patriotismo concuerdan perfectamente, debido a que ser patriota significa amar a la propia patria pero también reconocer y respetar a todas las demás.

Bebler considera que el marxismo no es una religión ni un dogma, sino una corriente de pensamiento político que abreva en los racionalistas franceses del siglo XVIII y en la tradición revolucionaria iniciada por los jacobinos. Estas teorías conciben al pueblo soberano como sujeto de derechos, que puede decidir sobre su independencia y defenderse 
contra toda forma de opresión. Los jacobinos, señala el autor, eran patriotas y adherían al mismo tiempo a los principios universales de igualdad y fraternidad, por ello concluye que "En la cuestión nacional, Marx ha adoptado totalmente la doctrina racionalista jacobina."24 Para Bebler, la cuestión nacional, tanto en Marx como en Rousseau, Robespierre y Lenin, está vinculada a la doctrina de la fraternidad de los pueblos, algo que sólo puede ser asegurado por el socialismo y que en el contexto de los años cincuenta, caracterizado por la interdependencia mundial, aparece como una evidente necesidad histórica.

La revista ubica a la situación del este europeo como una de las problemáticas del mundo contemporáneo que debe ser atendida porque allí se están desarrollando procesos que permiten comprender la importancia del "problema nacional". De este modo, Columnas... vincula los procesos que atraviesan los países de América Latina con las experiencias yugoeslavas o polacas a las que se empezó a llamar "comunismos nacionales", como los mismos autores citados indican en sus trabajos. Al presentar un artículo de Wladislao Gomulka, Secretario General del PC polaco entre 1956 y 1970, el copete de la nota destaca que es una cuestión que atañe no sólo a los países del mundo colonial sino también a aquellos que han emprendido el camino hacia el socialismo.

El texto de Gomulka parte de una afirmación distinta a la de Bebler al plantear que el socialismo es la contraposición de todo nacionalismo, porque su esencia reside en su carácter internacional. Pero esta misma afirmación lo lleva a preguntarse cómo hacer para consolidar un camino nacional (polaco) hacia el socialismo. La respuesta está en el reconocimiento de que el rumbo hacia ese objetivo siempre está determinado por condiciones históricas concretas, por eso en cada país la llegada al socialismo estará signada por su propia historia y será distinta al proceso vivido en la URSS, que fue realizado en otro contexto y bajo otros condicionamientos. Gomulka afirma que "el camino de la URSS no es ni plenamente necesario ni plenamente adecuado para otros pueblos". 25

Es en este punto en donde convergen ambos artículos. Bebler también considera necesario despegarse de la teoría de la "nación dirigente", porque la dirección de un pueblo sobre otro es una injerencia en sus asuntos internos y significa una forma de tutela que atenta contra el derecho a la libre disposición que cada pueblo debe ejercer sobre sí mismo. El autor sostiene que nada debe decretarse desde Moscú y recurre a la voz de Lenin para confirmar no sólo la necesidad sino la inevitabilidad de los comunismos nacionales: "Todas las naciones irán hacia el socialismo, ello es inevitable, pero no todas irán, en forma alguna, de la misma manera; cada una aportará su particularidad en una $u$ otra forma de democracia...,26

\footnotetext{
${ }^{24}$ Bebler, Ales. "Marxismo y Patriotismo", en Columnas del Nacionalismo Marxista. Avanzada de Frente Nacional. $\mathrm{N}^{\circ}$ 2, Agosto de 1957, 21-23.

${ }^{25}$ Gomulka, Wladislao. "El camino nacional en un país socialista", en Columnas del Nacionalismo Marxista. Avanzada de Frente Nacional. $\mathrm{N}^{\circ}$ 3, Setiembre de 1957, 11-12.

${ }^{26}$ Bebler, Ales. "Marxismo y Patriotismo", en Columnas del Nacionalismo Marxista. Avanzada de Frente Nacional. $\mathrm{N}^{\circ}$ 3, Setiembre de 1957, 27-30.
} 
La perspectiva antiimperialista de Columnas... incluye también a la URSS como una potencia que busca imponerse y orientar los rumbos de los países que quedaron bajo su órbita luego de la Segunda Guerra mundial. Las discusiones y posiciones que por entonces están presentes en países como Yugoslavia y Polonia son vinculadas con los procesos que están viviendo los países latinoamericanos en sus procesos de liberación, en los que la cuestión nacional se impone como la vía para alcanzarla.

\section{Conclusión}

En su trabajo sobre las revistas argentinas del siglo XX, Girbal-Blacha y QuattrocchiWoisson se preguntan si las publicaciones de "combate o debate", entre las que puede ubicarse Columnas..., son "simple eco de las tradiciones políticas argentinas o lugar de gestación de nuevas articulaciones políticas y culturales." ${ }^{27}$ En este sentido puede afirmarse que la revista, nacida al calor de las elecciones de 1957 en las que el peronismo se pronunció con el voto en blanco, representa un momento particular en el que comienza a estructurarse una corriente de pensamiento y acción, no elitista pero tampoco clasista, que apunta fundamentalmente a la alianza entre sectores medios y obreros unidos con un único objetivo: la lucha contra el imperialismo y sus agentes locales.

En medio de la proscripción del peronismo impuesta por el gobierno de facto y de la circulación de publicaciones clandestinas y semiclandestinas, Columnas... tuvo una existencia breve pero su lectura ofrece claves para conocer los tópicos y núcleos de debate que comenzaron a plantear sectores nacionalistas a partir de sus lecturas del marxismo, con el fin de articular una propuesta política para la liberación nacional que continuara y profundizara la tarea que ya había comenzado el gobierno peronista. Como señalan también las autoras, este "determinismo de los tiempos políticos" $" 28$ define la existencia coyuntural de la revista, aunque puede considerársela también como uno de los emprendimientos clave que luego del derrocamiento de Perón promovió la convergencia entre el pensamiento nacionalista ya existente y el marxismo. La caída de Perón abrió el camino para múltiples lecturas, como señala Devoto "Allí los intelectuales de la izquierda nacional encontraron una inesperada oportunidad para pasar de un lugar marginal a otro central en los debates de la izquierda argentina."29

En sus páginas escribieron figuras relevantes, por su reconocida participación en el mundo de las letras o por sus actuaciones políticas, provenientes de distintas tradiciones de pensamiento, pero todos compartían la perspectiva antiimperialista, la crítica a la izquierda tradicional, representada por los partidos socialista y comunista, y la necesidad de conformar un Frente Nacional para terminar con la dependencia económica y cultural del

\footnotetext{
${ }^{27}$ Girbal-Blacha, Noemí y Diana Quattrocchi-Woisson. Cuando opinar es actuar. Revistas argentinas del siglo XX. Buenos Aires: Academia Nacional de la Historia, 1999, 32.

${ }^{28}$ Ídem

${ }^{29}$ Devoto, op. cit., 120
} 
país. Fermín Chávez, Eduardo Astesano, Elías Castelnuovo y John W. Cooke participaban también de otros emprendimientos editoriales, publicaban libros o dictaban conferencias sobre estos temas, que se publicitaban en las contratapas de Columnas..., confirmando la existencia de una empresa cultural cuyo objetivo era generar y posicionar públicamente un núcleo de ideas que contribuyera a articular una propuesta política coherente. Estos autores son, además, referentes principales de la corriente de la Izquierda Nacional que se consolidaría en la década del sesenta y que contaría también con Jorge Abelardo Ramos y Juan José Hernández Arregui como figuras centrales.

Si el nacionalismo de la década del treinta se conformó como elitista, antiobrero e hispanista, el nacionalismo que se plasma en Columnas... en 1957 es producto de su tiempo y expresa los cambios que el peronismo introdujo en la matriz productiva, en las prácticas políticas y en la estructura social del país sumados a todos los debates y reposicionamientos ideológicos que generó. La revista valora como hitos importantes la Constitución de 1949, las nacionalizaciones, la participación política de la clase obrera, y en esta defensa reconoce al peronismo, como partido o movimiento, y a la habilidad política de su líder para tejer alianzas.

El peronismo había recogido dos ideas-fuerza provenientes del nacionalismo: la independencia económica y la soberanía política, y a ellas había sumado la bandera de la justicia social, dándole así al movimiento un apoyo de masas que volvía posible y deseable un acercamiento a las ideas marxistas. Columnas... también expresa y recoge parte de los planteos que se habían ido sucediendo en el campo de la izquierda tradicional a partir de 1945. Muchos de sus referentes se habían acercado al peronismo, porque reconocían el apoyo masivo que le brindaba la clase obrera e identificaban a la "cuestión nacional" como un factor clave para alcanzar la revolución socialista.

El nacionalismo que se consolidó después de 1955 mantuvo la línea antiimperialista y tomó a la "cuestión nacional" como eje central a través del cual articular un movimiento policlasista para defender los intereses de la nación. Así, el nacionalismo de Columnas... se presenta como popular, antiimperialista, promotor de la industria nacional, interesado por América Latina y Europa del Este y, a través de estas ideas, traza un rumbo político cuyo propósito es alcanzar definitivamente la liberación nacional. La revista expresa un núcleo de temas de los que otros sectores también están hablando, configurando un conjunto de problemas en torno a los que se articulan los debates políticos e ideológicos centrales de la etapa abierta con el derrocamiento del gobierno de Perón. 


\section{Bibliografía:}

Altamirano, Carlos. Peronismo y cultura de izquierda. Buenos Aires: Tesis, 2001.

Para un programa de historia intelectual y otros ensayos. Buenos Aires: Siglo XXI, 2005.

Amaral, Samuel. "Peronismo y marxismo en los años fríos: Rodolfo Puiggrós y el Movimiento Obrero Comunista, 1947-1955”, Investigaciones y Ensayos, 2000, ํ50, 171-194.

"La cuestión nacional en el "Manifiesto del Partido Comunista" de 1848. Documento de Trabajo N³35, Área Ciencias Políticas. Universidad del CEMA, 2006.

Agosti, Héctor. Nación y cultura. Buenos Aires: CEAL, 1982.

Astesano, Eduardo. Rosas. Bases del nacionalismo popular. Buenos Aires: Peña Lillo, 1960.

Buchrucker, Cristian. Nacionalismo y peronismo. Buenos Aires: Editorial Sudamericana, 1987.

Chávez, Fermín. Historicismo e iluminismo en la cultura argentina. Buenos Aires: Centro Editor de América Latina, 1982.

Devoto, Fernando. Nacionalismo, fascismo y tradicionalismo en la Argentina moderna. Una historia. Buenos Aires: Siglo XXI de Argentina Editores, 2002.

"Reflexiones en torno de la izquierda nacional y la historiografía argentina", en Devoto, Fernando y Nora Pagano (Editores) La historiografía académica y la historiografía militante en Argentina y Uruguay. Buenos Aires: Biblos, 2004.

Fiorucci, Flavia. Intelectuales y peronismo. 1945-1955. Buenos Aires: Editorial Biblos, 2011.

Gené, Marcela. Un Mundo Feliz: Imágenes de los trabajadores en el primer peronismo 1946-1955. Buenos Aires: Fondo de Cultura Económica, 2005.

Girbal-Blacha, Noemí y Diana Quattrocchi-Woisson. Cuando opinar es actuar. Revistas argentinas del siglo XX. Buenos Aires: Academia Nacional de la Historia, 1999.

Halperín Donghi, T. El revisionismo histórico argentino. Buenos Aires: Siglo Veintiuno, 1970.

La Argentina y la tormenta del mundo. Buenos Aires: Siglo Veintiuno, 2003.

Irazusta, Julio y Roberto Irazusta. La Argentina y el imperialismo británico. Buenos Aires: Tor, 1934.

Lvovich, Daniel. El nacionalismo de derecha. Desde su orígenes a Tacuara. Buenos Aires: Capital Intelectual, 2006.

Ranalletti, Mario. "De Frente (1953-1956) Una voz democrática y antiimperialista en la crisis final del primer peronismo", en Noemí Girbal-Blacha y Diana Quattrocchi-Woisson. Cuando opinar es actuar. Revistas argentinas del siglo XX. Buenos Aires: Academia Nacional de la Historia, 1999. 
Sosnowski, S. (ed.) La cultura de un siglo. América Latina en sus revistas. Buenos Aires: Alianza Editorial, 1999.

Stortini, Julio. "La perspectiva histórica de Eduardo B. Astesano. Comunismo, peronismo y revisionismo histórico." Ponencia en las $1^{\circ}$ JORNADAS NACIONALES DE HISTORIOGRAFÍA. Departamento de Historia/Facultad de Ciencias Humanas. Universidad Nacional de Río Cuarto Río Cuarto, 26 y 27 de Noviembre de 2015.

Terán, Oscar. Historia de la ideas en la Argentina. Diez lecciones iniciales, 1810-1980.Buenos Aires: Siglo XXI editores, 2008.

Nuestros años sesentas. La formación de la nueva izquierda intelectual argentina.19561966.Buenos Aires: Ediciones El cielo por asalto, 1993.

Williams, Raymond. Marxismo y literatura. Buenos Aires: Las Cuarenta, 2009. 